\title{
BEGINNING READING SKILLS IN THE PALM OF YOUR HAND
}

\section{Greg Larocque}

The following is a description of a technique for beginning levels of an approach to teaching reading skills. This technique is a very effective tool for introducing students to a variety of reading skills, for creating an awareness of language complexity, while at the same time getting them personally involved in the reading passage at hand.

For the teacher, this technique is a readily available guide to exploitation of ad hoc reading assigments, such as an article from one day's newspaper or a passage a student has just written. It also allows teachers to objectively evaluate "reading skills" textbooks, many of which are, in fact, "reading task" textbooks. However, this particular technique is not a panacea for every level of reading nor is it an exhaustive list of all skills, tasks, or question types.

\section{Some theoretical considerations}

For the purposes of this article, we will consider the three reading skills of "scanning," "skimming," and "reading for deeper comprehension" ("in-depth reading"). We will define scanning as the quick search for a particular piece of information in a given text. Skimming is perusing a text picking out bits and pieces here and there to be able to get the gist. Reading for deeper comprehension is a much closer examination of the text to get a great deal of information and, so, to build a quite complete understanding of it. All these techniques provide attack strategies for the reader to process text-bound information which he has some need to know.

Reading for deeper comprehension is more than just advanced scanning and skimming. In-depth reading usually demands a number of questions to determine if sufficient data for solid understanding have been processed by the reader. In-depth reading often takes the form of a complicated task, such as summarizing the text or writing a précis or getting to a destination from a series of instructions (a recipe, or someone's house for a party). In-depth reading also demands comprehension of large amounts of textual data as well as comprehension of stated and implied relationships in the text. This need to comprehend, in turn, requires that the reader has been able to infer meaning and relationships based on textual information. Tasks such as guessing the meaning of a word from context, or drawing conclusions are suggested here. In-depth reading also requires, for the sake of speed and long-term memory, that the reader process both textual and related personal data to formulate and reformulate hypotheses relating to the text, an aim of "prediction" tasks. 
However, before we get too deeply involved in reading skills theory, let us take a look at the technique. Once we have clarified the technique, the theory will be more readily understandable. Originally suggested by Earl Stevick in his own teacher training sessions, the grid (figure 1) begins to address a reading skills approach while keeping both reading objectives and language complexity in mind. The grid describes only the types and objectives of questions to ask, not the content. Figure 2 shows how the grid can be used with actual content. The text used to generate the questions was taken from Read Canada! 2 (English Development Section of the Linguistic Services Directorate) and is shown below.

\section{Reading Objectives Dimension}

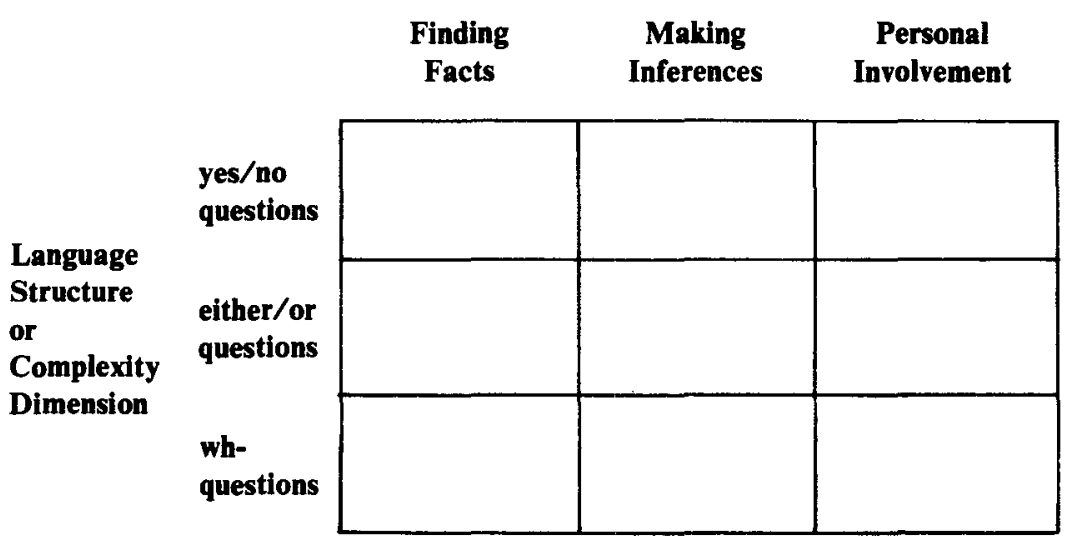

Figure 1. Grid for generating questions.

At dawn, Ostman saw that he was in a natural bowl high in the mountains with only one way to enter and leave. For seven days the lumberjack was a prisoner of the Sasquatch family. The son offered Ostman grass and sweet roots to eat. In return Ostman offered the son and the 'old man' some of his snuff. On the seventh day, the 'old man' took some of Ostman's tobacco powder and swallowed it. His eyes began to roll and he ran off to a spring for water. Ostman knew that his chance had come. He ran for the opening in the circle of mountains and was free. 
Reading Objectives Dimension

\begin{tabular}{|c|c|c|c|c|}
\hline Language & yes/no & $\begin{array}{l}\text { 1(a) } \\
\text { Was Ostman given only } \\
\text { grass to eat during his } \\
\text { captivity? }\end{array}$ & $\begin{array}{l}\text { I(b) } \\
\text { Is snuff a kind of tobacco? }\end{array}$ & $\begin{array}{l}\text { 1(c) } \\
\text { Do you know of any other } \\
\text { use of tobacco besides } \\
\text { cigarettes and snuff? }\end{array}$ \\
\hline $\begin{array}{l}\text { Structure } \\
\text { Or }\end{array}$ & $\begin{array}{l}\text { either/ } \\
\text { or }\end{array}$ & $\begin{array}{l}\text { 1(a) } \\
\text { Did the Sasquatch family } \\
\text { live in the mountains } \\
\text { or in a lowland valley? }\end{array}$ & $\begin{array}{l}2(b) \\
\text { Did the 'old man' like the } \\
\text { snuff or not? }\end{array}$ & $\begin{array}{l}2(c) \\
\text { Do you think tobacco harms } \\
\text { or benefits the user? }\end{array}$ \\
\hline Dimension & wh- & $\begin{array}{l}\text { 3(a) } \\
\text { How long was it before } \\
\text { Ostman escaped? }\end{array}$ & $\begin{array}{l}3(\mathrm{~b}) \\
\text { How did Ostman escape? }\end{array}$ & $\begin{array}{l}3(\mathrm{c}) \\
\text { Why do you think the Sasqu } \\
\text { family let Ostman live? }\end{array}$ \\
\hline 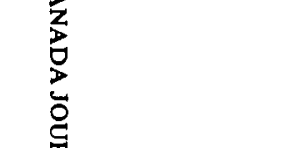 & Answer & $\begin{array}{l}1(a) \text { in the text- } \\
\text { "grass and roots." }\end{array}$ & $\begin{array}{l}\text { 1(b) inference-yes- } \\
\text { "offered snuff" \& } \\
\text { "took tobacco powder." }\end{array}$ & $\begin{array}{l}\text { 1(c) personal knowledge- } \\
\text { e.g., "yes. I think..." }\end{array}$ \\
\hline 旅 & & $\begin{array}{l}\text { 2(a) in the text-"in } \\
\text { the mountains" (Note } \\
\text { the "lowlands "dis- } \\
\text { tracter.) }\end{array}$ & $\begin{array}{l}\text { 2(b) inference-probably } \\
\text { not-"swallowed powder" } \\
\text { \& "ran for water." }\end{array}$ & $\begin{array}{l}\text { 2(c) personal opinion } \\
\text { e.g., "I think } \\
\text { it harms because..." }\end{array}$ \\
\hline 贾 & & $3(a)$ in the text-"7 days" & $\begin{array}{l}\text { 3(b) inference-“"offered } \\
\text { snuff" \& "old man ate" } \\
\text { "ran to spring" \& } \\
\text { "Ostman ran for opening." }\end{array}$ & $\begin{array}{l}\text { 3(c) personal conjecture, } \\
\text { e.g., "Well, perhaps..." }\end{array}$ \\
\hline
\end{tabular}

Figure 2. Grid used to generate questions for a mid-intermediate text. 
Many of the questions in the grid can be presented in a different format. They still accomplish the same objectives, but they provide a variety to the usual lists of questions students are often confronted with. The teacher could create multiple choice questions, for example:

1(a) During his captivity, Ostman ate... (check one) $\square$ meat $\square$ tobacco $\square$ grass only $\square$ grass and roots

Or a True/False format might also be interesting, for example:

1(a) During his captivity, Ostman was given only grass to eat. $T$ F

\section{The Role of the Reading Objectives Dimension}

As is evident from examining the grid and questions, the Reading Objectives Dimension is not an exhaustive key to skills-approach questions, nor is it meant to be. Rather, it provides a solid platform for more complex or other skill related activities by assuring that students get basic information from the text (the "a" questions), and that they will lock certain aspects of the text in their long-term memory by relating them to their own experiences (the " $c$ " questions).

It seems to be quite true that skimming is the bridge between simple factual discrimination (scanning) and complex text processing and task accomplishment (in-depth reading). It comes as no surprise, then, to see aspects of in-depth reading appear in the open-ended question in Making Inferences. Question 3(b), for example, requires that students have understood the information that certain text items provided ("offered snuff," "old man ate," "ran to spring," "Ostman ran") and have identified the process of sequence of events that took place. Questions of the 3(b) type tend to force students to:

1. understand textual information

2. make text-related relationships; and

3. accomplish a synthesizing task.

In addition, the entire "personal involvement" category encourages students to invest some part of themselves in their activity. This category makes a crucial link between the students' own experiences and their involvement in the activity they are performing. This consideration is perhaps most obvious in students who are particularly unmotivated because they see no relationship between their own concerns and needs and the activity the teacher wants to do. This category of questions encourages them to perceive the activity in their own terms and to validate their own life experiences within their second language learning.

Needless to say, focussing on either "a" or " $b$ " questions gives considerable skills practice for those students who are weak in either scanning or skimming. 


\section{The Role of the Language Structure/Complexity Dimension}

If we examine the question/answer technique, we would arrive at the following process:

(1) question asked by teacher $\rightarrow$ (2) question processed and understood by student $\rightarrow$ (3) question related to text by student $\rightarrow$ (4) answer found by student $\rightarrow(5)$ answer formulated and given by student $\rightarrow(6)$ answer confirmed by teacher.

The Language/Structure Dimension focusses specifically on (2), (3)/(4), and (5) above. Yes/No questions are often the most easily understood due to the limited language students need to understand (2), relate to text (3)/(4), and respond with (5). In the very formulation of the question exists one possible answer. Students need only relate question data to textual data to determine if the former is indeed correct. In addition, they need produce only minimal language (the words "yes" or "no") to respond to the question.

Either/Or questions have two possibilities explicitly stated, "Did $X$ or $Y$...?" This requires comprehension of both $\mathrm{X}$ and $\mathrm{Y}(2)$, relating each to the text (3), and responding with a whole phrasal $\mathrm{X}$ or $\mathrm{Y}$ element as response (4) rather than a "yes" or a "no." There is, in fact, a double simultaneous process happening here, whereas previously there was a single process.

Wh- questions are probably no more difficult to understand (2) than Yes/No questions. However, by their very nature they are much more complex to process and to answer, since one must supply words not included in the question. The primary clue to direct students to what to look for is in the question word itself (a person, thing, place, time, etc.). This clue must then be the basis of the search for the relevant textual information amidst all the textual information students have processed. It is this very open-endedness which requires extensive filtering and time (3)/(4). In addition, students must produce an answer which may or may not be the same as in the text, but certainly is radically different from the language of the question-unlike the two previous questions types.

\section{Conclusion}

Certain aspects of this technique are extremely familiar to teachers as activities they have always done. However, perhaps the variety these dimensions provide is something that has been daunting or impossible to implement on an ad hoc basis. This need not be the case.

The teacher's process of familiarization with this technique is quite easily achieved. For my part, I found I had to sit down with a text before class with the grid beside me, and write out the questions I wanted to ask. Soon, I found myself asking the "personal involvement" questions as 
"warm-up" and, while the students read the text, I drew the grid "in the palm of my hand" in pencil or pen and prepared questions in my mind to ask when the students had finished. It was not long before I was able to eliminate this visual crutch and could pose a great variety of questions quite fluidly.

As stated at the beginning, this grid is not a panacea for every level, skill, or task in a reading skills approach. However, it is readily applicable to any reading text, and does encourage real reading skill awareness on the part of both students and teachers.

The author would like to thank Earl Stevick, Deborah Doherty, Michael Sutton, and Howard Woods for their help in revising this article.

\section{REFERENCES}

Dubin, F., and Olshtain, E. (1981). Reading by all means. Reading, Mass.: Addison-Wesley.

Edwards, P. (1976) Reading problems: Identification and treatment. London: Heinemann Educational Books.

Grellet, F. (1981) Developing reading skills. Cambridge: Cambridge University Press.

McGinnis, D., and Smith, D. (1982). Analyzing and treating reading problems. New York: Macmillan.

Smith, F. (1971). Understanding reading. New York: Holt, Rinehart and Winston.

Smith, F. (1978). Reading. Cambridge: Cambridge University Press.

\section{THE AUTHOR}

Greg Larocque is a materials development and curriculum specialist with the Languages Training Program Branch of the Public Service Commission of Canada. A graduate of Columbia (New York) and Concordia (Montreal), he has given numerous workshops and training sessions on specific skills (reading, writing, listening) and ESL methodologies. He is also author of the ESP coursebook Administrative Writing. 